\title{
EL EJÉRCITO ROMANO DEL NOROESTE PENINSULAR DURANTE EL ALTO IMPERIO. ESTADO DE LA CUESTIÓN
}

POR

\author{
SANTIAGO CARRETERo VAQUERO
}

\section{RESUMEN - ABSTRACT}

Las recientes investigaciones arqueológicas centradas en el mundo militar romano de Hispania están aportando en los últimos años interesantes datos para reconstruir el devenir del ejército hispano en su principal marco de actuación, el noroeste peninsular. Pretendemos, con este artículo, no sólo insertar esa nueva información dentro del contexto general de su despliegue a lo largo de la época altoimperial, sino también cuestionar o clarificar ciertos aspectos referentes a su ocupación o las unidades que lo conforman.

Recent archaeological investigation about the Roman Military World in Hispania are adducing very interesting facts to reconstruct the transformation of the Roman Hispania Army in its main action area, the North-West. Along this paper we are trying no only to insert that new information into the general evolution of the Roman Army during the Early Empire, but also to clarify or to argue about its ocupation and its composing units.

\section{PALABRAS CLAVE - KEY WORDS}

Guerra Cántabras. Época altoimperial. Cuadrante noroeste. Ejército romano. Campamentos.

Cantabrian Wars. Early Empire Age. North-West Spain. Roman Army. Forts and Fortress.

El incremento del número de investigadores y equipos de trabajo que en los últimos años vienen centrando su actividad en algunos de los yacimientos y en los diversos aspectos del mundo militar romano del noroeste peninsular ha generado un significativo avance en la comprensión de dicho fenómeno. Ello ha dado lugar a una activa dinámica de estudios y publicaciones a través de los cuales se están clarificando numerosas incógnitas sobre la ubicación, características, estrategia, etc. de los asentamientos del ejército en este territorio.

Este avance no sólo tiene importancia por la incidencia directa en el conocimiento de los diversos aspectos que rodean al asentamiento y devenir histórico del ejército hispánico en este área durante la época altoimperial, sino que su despliegue y actividad posee tal entidad que se va a convertir en un elemento de primera magnitud a la hora de valorar el proceso de desarrollo de la zona norteña dentro de las estructuras sociales, políticas, económicas y administrativas del Imperio.

Aunque los contactos de Roma con algunos de los pueblos del norte peninsular se remontan al menos a la segunda mitad del siglo II a. C., bien mediante intercambios comerciales de escasa entidad con las poblaciones de la franja costera atlántica o por esporádicas incursiones militares, debemos esperar a los momentos iniciales del Imperio cuando circunstancias de índole muy diversa hacen que Augusto fije su atención en la anexión de estos territorios. 
La causa oficial que desencadena las hostilidades son las constantes razzias que cántabros y astures llevan a cabo contra los pueblos sometidos de la Meseta Norte, pero serán intereses geoestratégicos, económicos y de promoción personal del César los que se hallen en la génesis de la guerra. Así, la expansión hasta el mar Cantábrico para dotar al territorio de fronteras naturales, el conocimiento de la existencia de importantes recursos auríferos en la zona y, por último, el prestigio que supone para Augusto ser el que culmine la conquista de la Península Ibérica —obra iniciada dos siglos atrás y en la que habían participado los más prestigiosos militares romanos- serían realmente los motores que moverían al emperador a promover esta empresa.

La fase preparatoria arranca con campañas como la de Estatilio Tauro del año 29 a. C. contra cántabros, astures y vacceos, continuándose con nuevas intervenciones bélicas en los dos años siguientes. Estas incursiones, que si bien se adornan como verdaderas acciones de conquista, no serían más que meras incursiones tendentes a obtener información sobre la ubicación de los más importantes asentamientos de los enemigos, sus estrategias y capacidad guerrera, al tiempo que sirven de entrenamiento sobre el propio terreno para las tropas que en breve tendrán que acometer una expansión real y efectiva.

Tras estas premisas, en el año 26 a. C. se inician las hostilidades a gran escala. La táctica empleada para ello será el avance coordinado de varias columnas desde distintos frentes, desencadenando así los denominados bellum cantabricum y bellum asturicum. Este ataque conjunto de fuerzas, en el que participan unidades de la Lusitania y de la Tarraconense, se desarrollará durante dos años y supondrá un importante quebranto de la resistencia indígena aunque no una derrota total. Ello queda reflejado en el hecho de que el conflicto bélico continuará abierto hasta el año 19 a. C., si bien alternan los períodos de paz con campañas bélicas de menor intensidad que las acometidas en el momento álgido de la contienda.

Augusto vio en este conflicto el marco ideal para afianzar su prestigio personal como estratega, lo que le llevaría a participar personalmente en él. Sin embargo, la previsible fácil y rápida victoria no llegaba y desesperado y enfermo hubo de retirarse a Tarraco. La abrupta orografía del terreno, contraria a la estrategia militar romana, y el uso por parte de los indígenas de la táctica de guerrillas, rehuyendo el combate en campo abierto, van a conllevar una prolongación de la guerra no prevista, el concurso de un ingente número de unidades, tanto legionarias como auxiliares, y la participación de diversos generales romanos, entre ellos, el mejor de sus comandantes, Marco Vipsanio Agripa.

La descripción de estos episodios bélicos nos viene dada por cronistas como Floro, Orosio y Dión Casio, autores en cuyos textos - Epitome Gestae Romanae, Adversus paganus e Historia Romana - nos narran de una forma un tanto imprecisa y, en muchos casos, carente de rigor histórico la secuencia cronológica de las campañas y de los enfrentamientos, la identidad de los enclaves y accidentes geográficos mencionados, así como otra serie de referencias sobre esta contienda. Esa carencia de información y su falta de constrastación arqueológica están en la génesis de los problemas en los que se desenvuelve la historiografía moderna para reconstruir con cierta coherencia el desarrollo de las Guerras Cántabras.

Afortunadamente, la epigrafía y las sucesivas deductiones o donaciones de tierras a los veteranos licenciados tras la finalización de cada campaña incorporan nuevos testimonios a los ya mencionados exiguos documentos fiables proporcionados por las fuentes clásicas. Aun así falta la aportación que la arqueología puede hacer para desentrañar importantes interrogantes que todavía quedan por despejar y que son, en parte, el objetivo de este trabajo, es decir, la cuantía, identidad, movimientos y ubicación de las tropas que participan en la contienda.

En este punto debemos reseñar que, pese a los avances experimentados en este tema, éstos se centran primordialmente en las fases posteriores de ocupación y gestión del territorio y muy pocos son los que introducen nuevos datos sobre la conquista. 
Aun así, el análisis de los documentos proporcionados por las distintas fuentes posibilitan la reconstrución a grandes rasgos del panorama que rodea al operativo militar romano montado para acometer la conquista de estos territorios y que a continuación narramos de forma sucinta, puesto que ya ha sido tratado en numerosas ocasiones por distintos autores (García y Bellido, 1961: 114-160; Roldán Hervás, 1974: 159-230; Le Roux, 1982: 52-81; Morillo Cerdán, 1991: 161-168; Carretero Vaquero, 1993: 47-58; etc.).

Los efectivos movilizados para la conquista se pueden cuantificar en al menos siete legiones y un número sensiblemente mayor de tropas auxiliares. Entre las primeras cabe mencionar a la legio I, tal vez Augusta, II Augusta, IIII Macedonica, V Alaudae, VI Victrix y $X$ Gemina, quedando por el momento como interrogante la intervención de la legio IX Hispana ya que sólo su epíteto, recibido antes del $14 \mathrm{~d}$. C. puesto que con posterioridad se asienta en otras áreas del Imperio, la vincula al territorio hispano. Tampoco estamos en disposición de incluir en la contienda otras unidades legionarias, como la legio $X X$, de las que sólo poseemos algunas evidencias epigráficas que no implican su pertenencia a este ejército.

La acción de estas unidades legionarias se ve reforzada por una cifra sin determinar de auxilia, tanto de infantería - cohors - como de caballería - alae-, de cuya identidad sólo poseemos algunas referencias indirectas, basadas primordialmente en criterios probabilísticos. Debemos inferir que parte de las tropas auxiliares de cuya presencia en la zona tenemos constancia en la época inmediatamente posterior a la fase de conquista - cohors IIII Gallorum, cohors IIII Tracum Equitata, ala II Gallorum Sebosiana y ala II Tracum- pudieron formar parte de estos contingentes.

Esta fuerza expedicionaria estará formada desde los momentos iniciales del conflicto por las legiones I Augusta, II Augusta, V Alaudae y X Gemina, hecho que se puede constatar por la documentación de veteranos de estas unidades en las primeras deductiones generadas por las guerras norteñas. Con posterioridad, el recrudecimiento y la prolongación de la guerra harán necesaria la participación de nuevos efectivos y así su acción se verá reforzada con la inclusión de las legiones IIII Macedonica y VI Victrix.

La existencia de dos diferentes ámbitos de actuación en la contienda nos da la pauta para situar a las distintas unidades en uno de los dos frentes abiertos, el occidental o astur y el oriental o cántabro.

En cuanto a las unidades que participan en el primero de ellos, Orosio describe que el operativo del sector occidental estaba formado por tres legiones al mando de tres legados, sin que en ningún momento especifique la identidad de ninguna de ellas (VI, 21, 3-10). No obstante, la presencia de veteranos de las legiones $V$ Alaudae y $X$ Gemina en las deductiones efectuadas por el legado de la Lusitania y comandante de la fuerza expedicionaria contra los astures, Publio Carisio, así como el posterior asentamiento en la zona de las legiones VI Victrix y $X$ Gemina, nos permiten precisar el nombre de estas tres unidades como el núcleo central de las fuerzas del frente astur.

Durante el transcurso de la campaña del $26 / 25$ a. C. parece ser que estarían asentadas en el espacio comprendido entre las actuales localidades de Benavente-Astorga-León, lugar en el que se produciría el episodio del sorpresivo ataque de los astures contra estas fuerzas y que sería desbaratado gracias a la delación de los brigaecinos (Floro, II, 33, 54; Orosio, VI, 21, 9).

Por lo que respecta al sector oriental, éste va a contar igualmente con la participación de al menos otras tres legiones que avanzarán desde Segisama hacia el norte en tres columnas, una de las cuales será mandada personalmente por Augusto (Floro, II, 33, 46). Además de que la lógica nos hace suponer que en esta operación intervendrían las legiones restantes - I Augusta, II Augusta y IIII Macedonica-, tal hipótesis se ve confirmada por el hecho de que las dos primeras actuaron de forma conjunta en este frente bajo el mando directo de Augusto y son partícipes igualmente en el asentamiento de veteranos de las colonias Acci y Tucci (Roldán Hervás, 1974: 188-194), mientras que en el último caso se ve contrastada al levantar la legio 
IIII su campamento permanente, una vez finalizado el conflicto, en la localidad palentina de Herrera de Pisuerga.

Siguen existiendo, sin embargo, ciertas dudas a la hora de definir la ubicación concreta de Segisama, puesto que, pese a contar con evidencias arqueológicas romanas en el subsuelo de la localidad burgalesa de Sasamón, lugar que viene tradicionalmente identificándose con la Segisama de las fuentes, éstas no aportan ningún testimonio definitivo sobre la presencia de la base de la que va a partir la gran ofensiva contra el territorio cántabro.

El reconocimiento en dicho enclave de un recinto de 3 '5 has. a través de la fotografía aérea (Abásolo, 1975: 127-132) no se puede considerar como una prueba concluyente para demostrar este hecho ya que esa superficie es de todo punto insuficiente para albergar una unidad legionaria cuanto más para acoger un contingente tan numeroso como el que debió estar acantonado ahí. No obstante y pese a que las publicaciones más recientes siguen sin arrojar luz a este respecto (Abásolo y García, 1993), somos de la opinión que la falta de documentación existente no es óbice para excluir de momento la redución Sasamón/Segisama, sino que es cuestión de tiempo que se clarifique dicha hipótesis.

Como podemos observar los datos que se refieren a los asentamientos militares durante el conflicto son escasos y en muchas ocasiones cuestionables. A este panorama hay que sumar nuevos hallazgos, aún sin contratación arqueológica, que se han producido en los últimos años y que pueden arrojar alguna luz a la reconstrucción del desarrollo de las hostilidades. Estos descubrimientos se centran principalmente en el campamento de Villalazán, la presencia militar en Lucus Augusti y los recintos de los valles de Iguña y Toranzo.

En cuanto al primero de ellos, la información que de él poseemos viene dada en exclusividad por la fotografía aérea. El uso de esta técnica ha permitido localizar en la localidad zamorana de Villalazán un recinto rectangular de esquinas redondeadas que poseía una extensión de 12 ó 13 has. (Olmo Martín y Rodríguez Jiménez, 1993: 7), aunque con posterioridad sus dimensiones han sido ampliadas hasta las 22 has. (Olmo Martín, 1994-95: 115-118).

Por sus medidas - 565 por $405 \mathrm{~m}$.- podemos deducir que sirvió de albergue a una legión, y por la ausencia de estructuras y de hallazgos arqueológicos en su interior se puede inferir que tuvo una ocupación de carácter temporal.

Bajo estas premisas debemos dilucidar qué momento y cuáles fueron las circunstancias que promovieron el establecimiento de tropas en dicho paraje. Son varios las referencias que podrían enmarcar la presencia de este campamento dentro de la campaña militar que Estatilio Tauro emprendió en el año 29 a. C. contra vacceos, cántabros y astures, siendo éstas proporcionadas por la entidad de los yacimientos que lo circundan y que son, por un lado, el núcleo romano de el pago de El Alba y, por otro, los poblados de la II Edad de Hierro de El Castro y Valcuervo (Olmo Martín, 1994-95: 115). La identificación del primero con la mansio romana de Albocela y el hecho de que exista una dicotomía, tanto geográfica como cronológica, en cuanto al asentamiento - vacceo en el alto y romano en el valle- sirven para apuntar tal posibilidad (Carretero Vaquero, 1993: 54-55), si bien tal vez la regularidad de su perímetro se adecuaría mejor a la fisonomía que presentan los recintos castrenses a partir de época tiberiana.

Hoy por hoy, no existe ningún documento que permita averiguar qué legión estuvo aquí asentada. De comprobarse en un futuro la veracidad de la hipótesis planteada habría que restrigir la lista de las posibles unidades legionarias a aquéllas que posteriormente participarán de forma activa y desde un principio en el frente astur, la legio V Alaudae o la legio X Gemi$n a$, de tal modo que la experiencia adquirida contra estos pueblos se aprovecharía para las futuras campañas.

Menos incertidumbre parece existir a la hora de defender la presencia de una unidad legionaria durante el conflicto norteño en lo que con posterioridad será Lucus Augusti. En este caso, los abundantes hallazgos numismáticos de bronces de la serie de la caetra, acuñados para el pago del stipendium militare entre el 27 y el 23 a. C., constituyen una prueba prácti- 
camente concluyente para señalar el funcionamiento de una ceca militar móvil en el solar lucense (Ferrer Sierra, 1995: 24; Idem, 1996: 425-446). A ello hay que sumar la aparición en niveles arqueológicos antiguos de un bloque granítico del umbral de una puerta en el que se puede leer L VI (Rodríguez Colmenero, 1995: 16; Idem, 1996: 130, lám. 3). Esta inscripción se viene interpretando, no sin ciertas dudas por parte de algunos autores, como un irrefutable documento del asiento temporal de la legio VI Victrix en el lugar en algún momento de la gran campaña de los años $26 / 25$ a. C.

Por último - dentro de la fase de conquista-, ultimamente se han dado a conocer algunos de los posibles campamentos de campaña y asedio del frente oriental. La utilización de la fotografía aérea vuelve a ser fundamental a la hora de reconocer este tipo de asentamientos. Así, en los valles de Iguña y Toranzo parecen existir diversos recintos castrenses, entre los que destacan el de Cildá — con doble foso en forma de W, terraplenes, puertas en claviculae y unas dimensiones de 25 has.-, y el de Cueto Helguera —de menor tamaño, planta ovalada y el resto de características similares_, entre otros (Peralta, 1997: 14-23).

Todos ellos, más otro nuevo, el de La Collada de San Felices de Buelna, publicado en el Diario Montañes del viernes, 4 de septiembre, de 1998, y que posee como rasgos más característicos una supuesta división interna, lados rectilíneos y esquinas redondeadas, se han puesto en relación con el asedio de Aracillum, enclave cántabro que, por razones geográficas, estratégicas, etc., es identificado con el castro de la Espina de Gallegos (Ibidem, 22 y 23).

No vamos a entrar aquí a cuestionar la validez o no de esta nueva ubicación para uno de los parajes en los que se va a desarrollar uno de los episodios bélicos más conocidos de la resistencia cántabra puesto que no contamos con la información suficiente para ello, pero sí queremos plantear cierta prevención sobre la cantidad y calidad de los datos proporcionados por la fotografía aérea, sobre todo teniendo en cuenta la peculiar orografía del terreno. Es por ello que creemos necesario mostrar cierta prudencia a la hora de valorarlos, al menos hasta que éstos puedan ser contrastados con un levantamiento topográfico e intervenciones arqueológicas - que ya se están realizando-, de tal modo que no sólo se proceda a una correcta interpretación de los mismos sino también al establecimiento de un marco cronológico concreto.

Concluida la conquista de los últimos territorios hispanos se abre ahora una nueva fase, de ocupación y control, de la que afortunadamente poseemos un mayor grado de conocimiento.

A partir del año 19 a. C., fecha en la que oficialmente se da por concluida la guerra contra cántabros y astures, da comienzo la reorganización de los efectivos participantes en esta contienda, desplazando progresivamente unidades a otros puntos del Imperio. Este hecho no sólo está motivado porque el fin de la lucha supone el excedente de tropas en la zona sino también por infortunados acontecimientos fronterizos como el desastre de Varo.

Enmarcada en esta dinámica se inscribe el abandono del solar hispano por parte de las legiones II Augusta y V Alaudae, posiblemente en el 15 a. C., y I y IX Hispana, desconociéndose el momento en qué pudieron hacerlo estas últimas. De esta manera, desde los albores del siglo I d. C. el ejército hispano estará formado por tres unidades legionarias -IIII Macedonica, VI Victrix y X Gemina-, apoyadas por un número indeterminado de auxilia.

En el proceso de estabilización de estas tropas en el noroeste van a entrar a valorarse diversos factores que permitan adecuar la entidad de los contingentes y la ubicación de sus asentamientos a las funciones que van a tener que desempeñar. El frente al que estuvieron adscritas durante el conflicto va a ser un factor fundamental a la hora de circunscribir su emplazamiento. Igualmente, se tiene en cuenta la elección de posiciones estratégicas, normalmente en retaguardia con respecto al territorio recientemente "pacificado», para así contar con una base segura y tener libertad de movimientos en el hipotético caso de desencadenarse alguna revuelta. La elección de enclaves bien comunicados por vías naturales que permitan un rápido acceso a todos los puntos del territorio a controlar es otro aspecto importante en esta evaluación. Por último, aunque no menos fundamental, se encuentra el cumplimiento de 
una serie de requisitos indispensables para el levantamiento de un asentamiento de estas características, como son la presencia de abundantes recursos hídricos y de tierras para el cultivo de cereales y pastos.

Tras sopesar todos estos factores, la administración militar romana va a decantarse por el acantonamiento de las unidades legionarias en el mediodía de la coordillera cantábrica y de los Montes de León, situando una legión en el área cántabra - legio IIII Macedonica- y dos en la zona astur -legio VI Victrix y X Gemina-. La razón de esta desigualdad en la distribución de los efectivos radica en la existencia de importantes recursos auríferos en esta última y la consiguiente necesidad de contar con el concurso del ejército tanto en la explotación como en la vigilancia y control de las actividades mineras.

De esta manera, ya en época augustea, va a fijarse un entramado estable de establecimientos militares en el noroeste hispano centrado en tres bases legionarias y completado por otras de contingentes auxiliares. El alcance de esta cuidada planificación para la gestión de estos territorios será de tal entidad que posibilitará el despliegue permanente de tropas en dichos enclaves durante buena parte de la época altoimperial como consecuencia del alto valor estratégico de los puntos geográficos elegidos para tal fin.

La puesta en marcha de este operativo generará que Morillo Cerdán se cuestione si podría definirse como un limes sin fronteras (1996: 77-83). En sentido estricto no puede establecerse ninguna comparación entre lo que se ha puesto en marcha en esta zona con lo que ocurrirá en las áreas fronterizas del Imperio puesto que el concepto de limes implica una línea defensiva creada para separar el territorio propio de otros bajo dominio foráneo y potencialmente peligrosos. Sin embargo, subyacen puntos afines en ambas experiencias en cuanto que la organización militar desarrollada en el cuadrante noroeste peninsular podría ser un referente cercano a lo que algunos años más tarde se llevará a cabo en un área tan conflictiva como es el limes renano.

Independientemente del calificativo que se pueda o se quiera aplicar, el hecho es que a partir de los dos últimos decenios antes de Cristo va a dar comienzo un proceso de estabilización de las unidades que conforman el ejército de ocupación hispano y que, a tenor de los datos con los que contamos en la actualidad, estará concluido grosso modo en época medio o tardoaugustea.

La primera unidad legionaria en ocupar un asiento permanente será la legio IIII Macedonica que desde el 20/15 a. C. hasta el 39/40 d. C. estará acampada en la localidad palentina de Herrera de Pisuerga (Pérez González et alii, 1992). Por desgracia es prácticamente nula la información que poseemos acerca de las características de su recinto y de las estructuras ocupacionales, aunque existe por contra una abundante documentación sobre los distintos tipos de materiales arqueológicos y gracias a ella se puede avanzar en el conocimiento de diversos aspectos de la ocupación militar del enclave (Pérez González, 1989; Morillo Cerdán, 1992; Pérez González e Illarrequi Gómez, 1994: 259-271; etc,).

Adscrita a ella pudo hallarse la cohors IIII Tracum equitata (Santos Yanguas, 1981: 53), si bien desconocemos en qué lugar tendría su base.

Tras la marcha de la legio IIII Macedonica fuera de Hispania, en un momento que podría estimarse durante el reinado de Nerón, se instala en el antiguo solar campamental tropas de caballería, el ala Parthorum. Esta unidad, cuya permanencia se situaría hasta finales del siglo I d. C. o inicios de la siguiente centuria, pudiera adscribirse primero a la legio VI Victrix para pasar con posterioridad a depender de la legio VII Gemina (Pérez González, 1996: 95-96).

Algunos años después de que se establezca la legio $I I I I$ aparecerá en el valle zamorano de Vidriales la legio X Gemina. Es díficil precisar en qué momento se produce dicha llegada, pero el análisis de los materiales cerámicos más antiguos apuntan hacia un momento cifrado tal vez en torno al 15/10 a. C., es decir, algo posterior al anteriormente mencionado (Carretero Vaquero, e. p.). 
En este caso la fotografía aérea nos proporciona una nítida imagen de un recinto rectangular, de esquinas redondeadas, rodeado de un doble foso y con unas dimensiones de 17'5 has. (Carretero Vaquero y Romero Carnicero, 1996: 14).

La legión X será también la que se encuentre en la génesis de Asturica Augusta. El hallazgo de un doble foso en forma de $\mathrm{V}$ - fossa fastigatae - en las proximidades del escarpe noroccidental del alto en el que se ubica ha supuesto la resolución definitiva del posible origen militar de la ciudad (González Fernández, 1996: 85-90). Si a ello le sumamos que, junto a las inscripciones de milites de la legio X Gemina aparecidas en el subsuelo Astorga, se han recuperado dos grandes bloques graníticos con inscripciones de esta unidad legionaria (García Marcos y Vidal Encinas, 1995: 115), podemos despejar la incógnita de cuál de las legiones que actuan en el territorio astur es la responsable de la defensa de lo que será la capital del convento jurídico.

Queda, no obstante, una cuestión por resolver y es en qué orden se producen ambos asentamientos. Para ello debemos acudir de nuevo al estudio de los materiales cerámicos más antiguos localizados en el solar asturicense y que arrojan una datación pareja a la esgrimida para el campamento del valle, es decir, en torno al 15/10 d. C. (García Marcos y Vidal Encinas, 1996: 135). Esta paridad nos obliga a utilizar otro tipo de argumentos para despejar esta interrogante, como puede ser las reducidas dimensiones de su recinto militar zamorano. Si tenemos en cuenta que la superficie de los establecimientos legionarios suele cifrarse entre las 20 y 25 has., debemos inferir que las 17 '5 has. de la mencionada base del valle de Vidriales son insuficientes para albergar la totalidad de los efectivos de una legión y, por tanto, parte de ellos debieron acantonarse en el solar asturicense. Es por ello que nos inclinamos por la posibilidad de que la duplicidad en el asentamiento de la Legio X Gemina —amén de otros destinos provisionales en función de cometidos específicos (Fabré, Mayer y Rodá, 1986: 101)debió producirse de manera sincrónica o, cuando menos, en un reducido margen temporal, pero siempre partiendo de una primera posición estratégica en el valle y no al contrario.

Fuera cual fuese el orden en el establecimiento de esta unidad, la legio X Gemina permanecerá en Hispania hasta el año 63 d. C. C., año en el que momentáneamente será desplazada a Carnuntum para volver a territorio peninsular y salir definitivamente en el año $68 \mathrm{~d}$. C. Se ha formulado que, tras su regreso, se ubicaría en el mediodía hispano pero los materiales recuperados en el transcurso de las excavaciones arqueológicas practicadas en su base zamorana parecen apuntar hacia una continuidad en la secuencia ocupacional, lo que no permite descartar el retorno a su antiguo recinto.

Durante su estancia hispana va a contar con el apoyo de la cohors IIII Gallorum y del ala II Gallorum Sebosiana (Rabanal Alonso, 1990: 18), tropas auxiliares de las que desconocemos sus respectivos lugares de asiento.

De la primera de ellas, siempre se había aceptado su presencia en Castrocalbón, lugar en el que se habían localizado una serie de recintos rectangulares de esquinas redondeadas y de diverso tamaño y en cuyas inmediaciones había sido hallado un numeroso conjunto de hitos augustales en los que se menciona esta unidad (Loewinsohn, 1965: 26-49). Sin embargo, la multiplicidad de los mismos, la ausencia de evidencias de ocupación y otras circunstancias han llevado a distintos autores a interpretarlos como una consecuencia directa de prácticas de castramentación de los soldados de la cercana legio X Gemina, proponiendo entonces Le Roux que su base, al menos durante el reinado del emperador Claudio, se situaría algo más al norte, en el valle del Duerna (Jones, 1976: 59; Le Roux, 1982: 108; Carretero Vaquero, 1993: 56-57).

Por contra, no poseemos ningún dato sobre el asentamiento del ala II Gallorum Sebosiana. No obstante, el hallazgo de un recinto en Valdemeda, en la localidad leonesa de Manzaneda, cuya fecha de abandono se cifra entre los años 15/20 d. C. (Sánchez-Palencia, 1986: 128-136) y cuyas dimensiones - 4'2/4'5 has. - se adecúan a la superficie necesaria para 
albergar a un contingente de caballería de estas características pudiera en un futuro servir como argumento para su ubicación en dicho campamento. De ser cierta la datación del momento de abandono, a inicios del reinado de Tiberio, - hecho que por ahora nadie ha puesto en entredicho-, su perímetro de forma rectangular con las esquinas redondeadas resulta inadecuado para una cronología tan temprana, ya que este tipo de recintos se tiende a fechar a partir de época tiberiana. Con ello no queremos cuestionar la validez de la fecha propuesta para el campamento de Valdemeda, sino la rigidez que algunos autores pretender conferir a los distintos modelos campamentales existentes, siendo éstos orientativos y no definitorios.

De cualquier manera, quedan aún muchas tropas de auxilia por identificar y otras muchas por situar -ala II Tracum, ala Tautorum Victrix c. R., ala I Gigurrorum- por lo que esta idea no deja de ser una mera hipótesis.

Por último, las incógnitas existentes sobre la base de la legio VI Victrix parecen estar despejándose de forma definitiva. La recuperación de materiales julio-claudios en el subsuelo de León e, igualmente, la inscripción de L. Pupius Praesens, legado presumiblemente de esta legión al restituirse su epíteto en el adjetivo incompleto terminado en -trix (Alfoldy, 1969: 115; Le Roux, 1982: 106) dejaban abierta esa posibilidad. Afortunadamente, en los últimos años no sólo se han incrementado notablemente los hallazgos cerámicos fechables en momentos anteriores a la ocupación de enclave entre los ríos Bernesga y Torío por la legio VII Gemina sino que además éstos han venido acompañados por el descubrimiento de una serie de vestigios constructivos identificables con estructuras militares.

Las excavaciones realizadas en el patio del edificio Pallarés (Miguel Hernández y García Marcos, 1993: 175-206), en el barrio de San Pedro (Vidal Encinas y García Marcos, 1996: 151) o las más recientes y aún inéditas del barrio de Santa Marina arrojan una ocupación castrense de esta unidad desde época medio-tardo augustea hasta el año 69/70 d. C., años en el que se produce su salida de Hispania.

Todos los datos expuestos nos permiten perfilar un panorama bastante nítido de los efectivos diseminados por el noroeste peninsular durante la primera del siglo I d. C. Evidentemente el mantenimiento de este operativo, decreciente en cuanto número, no está abocado unicamente al desempeño de funciones estrictamente militares, sino que su actividad abarca un amplio arco de cometidos.

Será el encargado de canalizar la belicosidad de los jóvenes indígenas en beneficio de Roma de manera que, mediante su reclutamiento, se crearán numerosas unidades de auxilia cuyos epítetos aluden a sus respectivos orígenes étnicos y que, una vez asimiladas al esquema militar romano, serán transferidas ya en época julio-claudia a diversos puntos del Imperio; suplirá o complementará a la incipiente administración civil hasta que ésta logre extenderse completamente por las áreas periféricas; facilitará la articulación del territorio mediante su participación en la construcción de la red viaria; intervendrá de forma directa en las obras, vigilancia y transporte de los recursos auríferos. Por otro lado, los campamentos serán un foco de atracción para la población indígena, sustituyendo el papel que en otras provincias con un mayor desarrollo urbano desempeñan las ciudades, y promoverán el surgimiento de industrias civiles, sobre todo en el ámbito de los talleres cerámicos. En definitiva, el ejército será un elemento vertebrador fundamental en este territorio, omnipresente en todos los ámbitos, tanto económico como administrativo, social, político, etc.

La guerra civil generada tras la muerte de Nerón va a suponer una momentánea quiebra en la dinámica iniciada ya con Augusto y basada en la racionalización de los efectivos. La candidatura al trono de Galba incidirá en el regreso de las legiones I Adiutrix y X Gemina y en la creación de la VII Gemina, unidades que imaginamos vendrían acompañadas de otras auxiliares.

Este breve episodio termina con la ascensión al poder de Vespasiano $\mathrm{y}$, de nuevo, los problemas en la frontera del Rin, en este caso la revuelta bátava de Iulio Civilis, provoca la 
necesidad de contingentes de refuerzo en este sector del limes y el consiguiente traslado de tropas desde Hispania. Así, se produce la «desmilitarización» del noroeste al desplazarse hacia bases renanas las legiones I Adiutrix, VI Victrix y X Gemina.

Desde este momento hasta la llegada de la legio VII Gemina el ejército hispano debió estar formado exclusivamente por tropas auxiliares, sin que por ahora podamos concretar algún dato sobre su número o identidad, salvo quizás la posible presencia en Herrera de Pisuerga del ala Parthorum y una posible cohorte.

En el 73/74 d. C. se inaugura una nueva fase definida por la presencia de una única unidad legionaria en el territorio peninsular, la legio VII Gemina, legión de reciente creación bajo Galba- cuya bisoñez se había evidenciado en la batalla de Cremona donde sufrió numerosas bajas. Para el levantamiento de su base permanente se va a elegir el enclave situado en la confluencia de los ríos Bernesga y Torío, lugar que con anterioridad había sido ocupado por la legio VI Victrix. Este hecho incide nuevamente en el alto valor estratégico de dicho paraje puesto que, además de poseer una óptima posición defensiva, se ubica en un paso natural entre la Meseta y el territorio al norte del macizo cantábrico y de fácil comunicación tanto con el área galaica como con el valle del Ebro.

Afortunadamente, en los últimos años se empiezan a conocer algunos datos sobre las estructuras constructivas y el sistema defensivo de este recinto. Las excavaciones arqueológicas practicadas en distintos puntos de la ciudad de León han puesto al descubierto una serie de evidencias de esta ocupación, como puede ser el posible barracón y la vía aledaña de la calle Serranos (García Marcos, 1996: 79) u aquellas otras que afectan a la muralla.

A través de estas últimas y del análisis de antiguas intervenciones se ha podido confirmar la existencia de un recinto altoimperial que se encuentra en la actualidad enmascarado por el trazado murario de época tardía y que se puede describir como formado por un muro de 1'80 m. elaborado con dos paramentos de piedra y un núcleo de argamasa (Campomanes Alvare1o, 1997: 134-136). De este recinto, ceñido al sistema defensivo bajoimperial, se han exhumado recientemente parte de las estructuras que conforman la porta principalis sinistra bajo el firme de la Puerta del Obispo, hallándose estos restos aún inéditos (Ibidem: 146).

León no será la única base para los efectivos de esta unidad sino que alguno de sus destacamentos o vexillationes va a establecerse en el valle de Vidriales, volviendo a recuperar parte del antiguo solar campamental. Prueba de ello son los ladrillos paralelepípedos con la marca L VII G F recuperados en la zona suroeste del mismo y cuya aparición plantea varias hipótesis en función de la gran amplitud cronológica que poseen los sellos de la Legio VII Gemina Felix. La primera de ellas es la que se articula en torno a la presencia de este destacamento de infantería antes de la llegada del ala II Flavia, mientras que la segunda incidiría en un asentamiento sincrónico de ambas (Carretero Vaquero y Romero Carnicero, 1996: 21-22).

A falta de pruebas concluyentes que avalen uno u otro supuesto propugnamos una vía intermedia: la presencia de soldados de la legio VII Gemina antes y durante la estancia de la unidad de caballería. La aparición de estos ladrillos implica la existencia de construcciones estables y, por tanto, el asentamiento de estas tropas durante un prolongado período temporal, lo que unido a la pronta arribada del ala, permiten apuntar tal posibilidad.

Independientemente de cuál sea el alcance de esta ocupación legionaria, lo que queda fuera de toda duda es la reutilización del antiguo solar campamental de la Legio X Gemina por parte de una unidad auxiliar, el ala II Flavia Hispanorum civium Romanorum. Con ello, el aprovechamiento de nuevo de un lugar que previamente había servido de base a otro contingente de tropas, se puede articular el eje básico sobre el que basculará la actividad del ejército hispano altoimperial: Herrera de Pisuerga con la legio IIII Macedonica, el ala Parthorum y una cohorte; León con la legio VI Victrix y la legio VII Gemina; y Rosinos de Vidriales con la legio X Gemina y el ala II Flavia. 
En cuanto a la última de ellas, se establece en un campamento de 4'7 has., tiene forma rectangular y esquinas redondeadas. Sus dimensiones resultan excesivas para acoger a una unidad quinquenaria de caballería. Tal vez el hallazgo de armamento de infanteria en el interior del mismo así como la presencia de esos ladrillos con la marca L VII G F sean la clave para entender esa sobredimesión del recinto. Es decir, continuando con la hipótesis ya planteada, esta base militar quizás estuviera proyectada para albergar no sólo a un ala de caballería sino también a algún destacamento legionario.

El estudio de los materiales arqueológicos desenterrados durante la exhumación de parte de los edificios y vías situadas en los latera praetorii, junto a la porta principalis sinistra, nos permite cifrar su estancia en Petavonium desde principios de la década de los $80 \mathrm{~d}$. C. hasta un momento indeterminado de finales del siglo II o inicios del s. III (Carretero Vaquero, e. p.). No obstante, los datos aportados por la epigrafía sirven para prolongar esta ocupación al menos hasta el $252 \mathrm{~d}$. C., momento en el que esta unidad, nominada con nuevos epítetos - ala II Flavia Galliana Volusiana- erige una inscripción al numen y a la maiestas del emperador Treboniano Galo y su hijo Volusiano.

Las continuadas intervenciones arqueológicas nos ha proporcionado una ingente documentación sobre este recinto y su guarnición, pudiendo así inferirse las características del sistema defensivo, así como su evolución a lo largo de su historia (Carretero Vaquero y Romero Carnicero, 1996: 25-29; Carretero Vaquero, Romero Carnicero y Martínez García, e. p.); la ocupación del sector de los latera praetorii próximo a la porta principalis sinistra, zona en la que, además de recuperar una gran cantidad de materiales arqueológicos, sirve para constatar las técnicas constructivas de calles y edificios, de forma que los datos aportados por ambos permiten esclarecer a grandes rasgos una secuencia cronológica del asentamiento marcada por la reestructuración del trazado urbanístico en el comedio de la segunda centuria (Carretero Vaquero y Romero Carnicero, 1996: 30-38).

De igual forma, se puede mencionar que tanto las inscripciones recuperadas como algunos de los hallazgos cerámicos posibilitan la identificación no sólo de los diversos prefectos que se sucedieron en la dirección del Ala II Flavia (Martin Valls, Romero Carnicero y Carretero Vaquero, 1995: 331-345) sino también de diversos soldados que sirvieron bajo su mando (Carretero Vaquero, 1998: 83).

Nuestro vínculo con el proyecto arqueológico de Petavonium nos daría pie a seguir describiendo multitud de aspectos que, relacionados con este asentamiento castrense, están siendo en la actualidad analizados. Sin embargo no es éste el propósito que perseguimos con este estudio y, menos aun, teniendo en cuenta que, al ser uno de los asentamientos militares romanos cuya investigación está avanzando de forma más continuada en los últimos años, los nuevos hallazgos se van sucediendo a un ritmo acelerado.

En un estadio de investigación más consolidado se encuentra el campamento de Aquis Querquennis o Aquae Querquernnae, en la orensana localidad de Baños de Bande. Desgraciadamente, el hecho de situarse en la orilla del pantano de As Conchas genera que durante buena parte del año éste quede parcialmente cubierto por sus aguas, lo que limita enormemente el alcance de las actuaciones arqueológicas en su interior. Pese a ello, en las últimas décadas se han exhumado amplios sectores del mismo, empezando por la muralla que comprende una superficie rectangular con las esquinas redondeadas de 3 has., las portae principalis sinistra y decumana, dos horrea, varios contubernia o barracones y el posible praetorium (Rodríguez Colmenero y Hervés Reigoso, 1992; Caamaño Gesto, 1996: 113-114).

No se conoce, sin embargo, qué guarnición tiene su asiento en este recinto castrense, aunque sus dimensiones se adecúan a las necesidades de una cohorte quinquenaria. En función de este dato y descartando las unidades auxiliares de infantería ya establecidas en otras bases se ha barajado la posibilidad de que albergue a la cohors I Gallica, destacamento subordinado al mando de la legio VII Gemina. Fuesen los que fueran sus ocupantes, el campa- 
mento tiene un período de vida que se puede situar entre los primeros decenios de la dinastía flavia y los años centrales de la siguiente centuria.

De implantación más tardía es el de Cidadela, en la provincia de A Coruña, cuya erección se fecha a comienzos de la segunda centuria y perdura hasta un momento avanzado del siglo IV. Las numerosas tejas con marca de la cohors I Celtiberorum son el testimonio clave para afirmar la presencia de esta unidad en dicho enclave. Este campamento, al igual que los dos anteriores, adecúa su forma a un rectangulo con las esquinas redondeadas, aunque posee unas dimensiones ligeramente inferiores - 2'4 has - al que presenta el recinto orensano. De él se han exhumado gran parte del sistema defensivo y dos edificios de planta compuesta que se identifican con los principia y el praetorium (Caamaño Gesto, 1996: 114-116).

El estudio comparativo de los campamentos correspondientes a esta última fase pone de manifiesto la existencia de algunas características en común, entre las que destacan: su ubicación a lo largo de vías de comunicación - Legio, como sede campamental, en un importante cruce viario; Petavonium en la vía XVII, que une Bracara Augusta con Asturica Augusta a través de Aquae Flaviae; Aquae Querquernnae en la vía XVIII o Via Nova, calzada que comunica igualmente ambos núcleos; y A Cidadela entre Brigantium y Lucus Augusti-; y la fisonomía de su perímetro, rectangular y con esquinas redondeadas.

Estos rasgos también están presentes en un nuevo recinto campamental descubierto en las proximidades de Uxama Argaela, en la localidad soriana del Burgo de Osma. La fotografía aérea se vuelve a erigir en una herramienta fundamental a la hora de localizar este tipo de asentamientos y así, en este caso, sirve para identificar un establecimiento de 2'3 has., del cual sólo se nos informa en la publicación en la que se da a conocer su adscripción a época altoimperial (García Merino, 1996: 269-274). Esta escasez de datos no permite inscribir esta guarnición dentro de una fase concreta, por lo que deberemos esperar a futuras labores de campo, bien sean trabajos de prospección o de excavación, para poder concretar su cronología o la identidad de sus ocupantes.

Como puede observarse, el operativo militar que impera tras la llegada de la Legio VII Gemina gira en torno al control del sector occidental del norte peninsular. Desde un principio existía ya una mayor concentración de tropas en este territorio, diferencia que se va a incrementar en esta fase por una cuestión fundamentalmente, la existencia de grandes recursos auríferos. Prueba de ello es el desplazamiento de vexillationes de la legio VII Gemina, cohors I Gallica, cohors I Celtiberorum y ala II Flavia a los pies del Teleno - Villalis-, al menos durante las últimas décadas del siglo II d. C., con la exclusiva misión de controlar y proteger las explotaciones mineras de dicha zona.

En definitiva, el conocimiento sobre el ejército hispano altoimperial se ha incrementado notablemente en la actualidad, aunque de forma desigual. Siguen evidenciándose grandes carencias para la reconstrucción de la fase de conquista, mientras que se avanza de forma clara en la comprensión de las fases posteriores, especialmente en la que se inaugura con la llegada de la legio VII Gemina.

Con la realización de este artículo hemos intentado perfilar de manera concisa el estado en que se encuentra la investigación de este tema en la actualidad, dejando para ello aparcados aspectos consustanciales a la presencia del ejército y de gran interés para valorar la imbricación militar en el territorio y su influencia en la «romanización» del noroeste. La amplitud derivada de la diversidad y disparidad de esos aspectos inherentes al elemento castrense - económicos, administrativos, sociales, religiosos, etc.- hace imposible su inclusión en este estudio ya que con ellos rebasaríamos las dimensiones de un trabajo de este tipo.

Pese a todo no nos resistimos a mencionar que uno de los campos en el que los hallazgos permiten realizar un mayor avance es el esclarecimiento de los sistemas de abastecimiento del ejército del noroeste, tanto de víveres como de otros utensilios necesarios para la vida castrense, especialmente los cerámicos, y cómo, a raiz de la integración del estamento militar 
en el territorio, se va a producir una transformación en la mentalidad de la sociedad civil norteña, lo que se va a reflejar en la creación de incipientes industrias locales.

Como colofón, simplemente decir que el gran dinamismo que están experimentado los estudios sobre el ejército hispano, los distintos factores relacionados con él y con el territorio que ocupa se encuentran en la génesis de la organización del I Congreso de Arqueología Militar romana en Hispania en Segovia durante los días 5 al 8 de Noviembre de 1988. Con toda seguridad, esta reunión científica servirá para dar a conocer nuevas cuestiones o avanzar en el conocimiento de otras aquí planteadas y se erigirá, sin lugar a dudas, en un hito fundamental en la consolidación del status que el mundo militar romano de la Península Ibérica está adquiriendo dentro de la Arqueología española.

Santiago Carretero Vaquero

Departamento de Arqueología y Prehistoria, Universidad de Valladolid

\section{BIBLIOGRAFÍA}

\section{Fuentes clásicas:}

Dion Cassio, Historia Romana.

Floro, Epitome Res Gestae.

Orosio, Adversus paganos.

\section{Publicaciones recientes:}

ABÁSOlo, J. A. (1975): «Notas sobre el campamento romano de Sasamón (Burgos)», Pyrenae, 11, pp. 127-132.

ABÁSOlo, J. A. y GaRCÍA, R. (1993): Excavaciones en Sasamón (Burgos), Excavaciones Arqueológicas en España, 164, Madrid.

ALFOLDY, G. (1969): Fasti Hispanienses, Senatorische Reichsbeamte und Offiziere in den Spanischen Provinzen des römischer Reiches von Augustus bis Diokletian, Wiesbaden.

CAAMAÑo GeSTO, J. M. (1996): «Los campamentos romanos de Galicia», en Fernández Ochoa, C. (coord.), Los finisterres atlánticos en la Antigüedad. Epoca prerromana y romana, Madrid, pp. 113-117.

CAMPOMANES AlVARELO, E. (1997): «Algunas cuestiones en torno a la primera muralla de la Legio VII Gemina», Lancia, 2, pp. 129-148.

CARRETERo VAQUeRo, S. (1993): «El cuadrante noroeste peninsular en época romana: los efectivos y sus establecimientos», Brigecio, Revista de Estudios de Benavente y sus tierras, 3, pp. 47-73.

CARretero VAquero, S. (1998): «Grafitos del campamento romano de Petavonium (Rosinos de Vidriales, Zamora)", Brigecio, Revista de Estudios de Benavente y sus tierras, 8, pp. 47-84.

CARRETERo VAQUero, S. (e. p.): El campamento romano del Ala II Flavia en Rosinos de Vidriales (Zamora): La cerámica. Tesis Doctoral inédita.

CARretero VAquero, S. y Romero CARnicero, M. V. (1996): Los Campamentos Romanos de Petavonium (Rosinos de Vidriales, Zamora), Zamora.

Carretero Vaquero, S., Romero Carnicero, M. V. y Martínez García, A. B. (e. p.): «Las estructuras defensivas del campamento del Ala II Flavia en Petavonium (Rosinos de Vidriales, Zamora)», Actas del II Congreso de Arqueología Peninsular, Septiembre, 1996, Zamora.

FABRÉ, G., MAYER, M. y RoDÁ, I. (1986): «Las inscripciones romanas de la Provincia de Barcelona», Caesaragusta, 63, pp. 87-102.

FERRER SIERRA, S. (1995): «Lugo, ceca monetal: el primer banco de la ciudad», en Lucus Augusti. Urbs Romana. Los orígenes de la ciudad de Lugo, Lugo, p. 24. 
FERRER SIERRA, S. (1996): «El posible origen campamental de Lucus Augusti a la luz de las monedas de la caetra y su problemática», en Rodríguez Colmenero, A. (coord), Lucus Augusti. I. El amanecer de una ciudad, A Coruña, pp. 425-446

GARCÍA Y BELlido, A. (1961): «El «Exercitus Hispanicus» desde Augusto a Vespasiano, AEArq, XXXIV, pp. 114-160.

GarCía Marcos, V. (1996): «La Romanización Urbana: Asturica Augusta y la implantación Romana de León", ArqueoLeón. Historia de León a través de la Arqueologia, León, pp. 69-81.

García Marcos, V. y VIdAL EnCINAS, J. M. (1995): «Asturica Augusta y Castra Legionis VII Geminae en la Asturia Cismontana», en VV.AA., Astures. Pueblos y culturas en la frontera del Imperio romano, Gijón, pp. 113-128.

García Marcos, V. y Vidal EnCiNAS, J. M. (1996): «Asturica Augusta: recientes investigaciones sobre su implantación y desarrollo urbano», en Fernández Ochoa, C. (coord.), Los finisterres atlánticos en la Antigüedad. Epoca prerromana y romana, Madrid, pp. 135-146.

GARCÍA MERINo, C. (1996): «Un nuevo campamento romano en la cuenca del Duero: el recinto campamental de Uxama», AEArq, 69, pp. 269-274.

GONZÁLEZ FERNÁNDEZ, M. L. (1996): «Consideraciones sobre el origen militar de Asturica Augusta», en Fernández Ochoa, C. (coord.), Los finisterres atlánticos en la Antigüedad. Epoca prerromana y romana, Madrid, pp. 85-90.

JONES, R. F. J. (1976): «The roman military ocupation of North-West Spain», Journal of Roman Studies, LXVI, pp. 45-66.

LE RouX, P. (1982): L'armée romaine et l'organisation des provinces ibériques d'Auguste a l'invasion de 409, París.

LOEWINSOHN, E. (1965): «Una calzada y dos campamentos romanos del Conventus Asturum», AEArq, XXXVIII, pp. 26-49.

Martin Valls, R., Romero Carnicero, M. V. y Carretero VaQuero, S. (1995): «Aras votivas de Petavonium», Zephyrus, XLVIII, pp. 331-345.

Miguel HernándeZ, F. y García Marcos, V. (1993): «Intervención arqueológica en el patio del centro cultural Pallarés (León)», Numantia, 4, pp. 175-206.

MORILlo CERDÁN, A. (1991): «Fortificaciones campamentales de época romana en España», AEArq, 64, pp. 135-190.

MORILlo CERDÁN, A. (1992): Cerámica romana de Herrera de Pisuerga (Palencia-España). Las lucernas, Santiago de Chile.

MORILlo CERDÁN, A. (1996): «Los campamentos romanos de la Meseta Norte y el Noroeste: ¿un limes sin fronteras?», en Fernández Ochoa, C. (coord.), Los finisterres atlánticos en la Antigüedad. Epoca prerromana y romana, Madrid, pp. 77-83.

Olmo MARTíN, J. DEL, y RODRÍGUEZ JiMÉNEZ, J. (1993): «Arqueología áerea en Castilla y León», Revista de Arqueología, 142, pp. 6-7.

OLMO MARTíN, J. DEL (1994-95): «Arqueología aérea en tres núcleos campamentales romanos de Zamora y León, Brigecio, Revista de Estudios de Benavente y sus tierras, 4-5, pp. 109-118.

PERALTA LABRADOR, E. (1997): «Arqueología de las guerras cántabras. Un campo de batalla en las sierras de Iguña y Toranzo», Revista de Arqueología, n 198, pp. 14-23.

PÉREZ GonZÁlez, C. (1989): Cerámica romana de Herrera de Pisuerga (Palencia-España). La terra sigillata, Santiago de Chile.

PÉREZ GONZÁLEZ, C. (1996): «Asentamientos militares en Herrera de Pisuerga», en Fernández Ochoa, C. (coord.), Los finisterres atlánticos en la Antigüedad. Epoca prerromana y romana, Madrid, pp. 91-102.

PÉREZ GonZÁLEZ, C. et alii (1992): Papeles Herresenses I, Palencia. 
Pérez GonZÁleZ, C. e Illarrequi GómeZ, E. (1994): «Un taller de útiles oseos de la Legión IIII Macedónica», $I^{\circ}$ Congresso de Arqueologia Peninsular, Actas IV, Porto, 1993, Trabalhos de Antropologia e Etnologia, XXXIV, 3-4, pp. 259-271.

RABANAL Alonso, M. A. (1990): La romanización de León, León.

RODRíGuez COLMENERo, A. (1995): «Lugo, capital romana del extremo noroeste peninsular. Génesis de una ciudad», en Lucus Augusti. Urbs Romana. Los origenes de la ciudad de Lugo, Lugo, pp. 11-18.

RodríGuez COLMENERO, A. (1996): «Lucus Augusti, capital de la Gallaecia septentrional», en Fernández Ochoa, C. (coord.), Los finisterres atlánticos en la Antigüedad. Epoca prerromana y romana, Madrid, pp. 129-133.

Rodríguez Colmenero, A. y Hervés ReIGoso, F. M. (1992): Aquis Quequennis. Campamento romano y ciudad-mansión viaria, Ourense.

ROLDÁn HERVÁs, J. M. (1974): Hispania y el ejército romano. Contribución a la historia social de la España Antigua, Salamanca.

SÁNCHEZ-PALENCIA, F. J. (1986): «El campamento romano de Valdemeda, Manzaneda (León): ocupación militar y explotación aurífera en el N.W. peninsular», Numantia, II, pp. 128-136.

SANTOS YANGUAS, N. (1981): El ejército romano y la romanización de los astures, Oviedo.

VidAl EnCINAS, J. M. y García MARCos, V. (1996): «Novedades sobre el origen del asentamiento romano de León y de la Legio VII Gemina», en Fernández Ochoa, C. (coord.), Los finisterres atlánticos en la Antigüedad. Epoca prerromana y romana, Madrid, pp. 147-155. 